\title{
Saberes científicos e pedagógicos de conteúdo em Ciências Naturais nos anos iniciais do ensino fundamental em Cuiabá - MT
}

\author{
Scientific and pedagogical knowledge of content in Natural \\ Sciences in the early years of elementary school in Cuiabá - MT
}

\author{
Zélia Alves dos SANTOS 1 \\ Marcel Thiago Damasceno RIBEIRO²
}

\begin{abstract}
Resumo
Este trabalho é um recorte de uma pesquisa de mestrado e busca compreender e relatar a experiência de pedagogos, ao trabalharem com a disciplina de Ciências Naturais, nos anos iniciais do Ensino Fundamental. Nesse sentido, a questão norteadora da pesquisa é: como se configuram e se expressam saberes científicos e pedagógicos de conteúdos de Ciências Naturais subjacentes à docência de professores nos anos iniciais, ao relatarem o ensino que realizam no Ensino Fundamental? Assume-se a abordagem qualitativa, partindo dos pressupostos da Pesquisa Narrativa como método de pesquisa. Como registros de informaçóes se opta por questionário e entrevista semiestruturada. Para analisar e produzir os textos de campo se adota a Análise Textual Discursiva. Os resultados legitimam contrariedades denunciadas nos relatos dos pedagogos que ensinam Ciências Naturais, pois apontam deficiências na formação inicial sobre as metodologias do trabalho pedagógico em Ciências Naturais.
\end{abstract}

Palavras-chave: Educação em Ciências. Saberes Docentes. Ensino Fundamental.

\begin{abstract}
This paper is a clipping of a master's research and seeks to understand and report the experience of educators working with the discipline of Natural Sciences in the early years of elementary school. In this sense, the guiding question of the research is: How to configure and express scientific and pedagogical knowledge of Natural Sciences content underlying the teaching of teachers in the early years, when reporting the teaching they perform in elementary school? The qualitative approach is assumed based on the assumptions of Narrative Research as a research method. As information records, a questionnaire and semi-structured interview are chosen. To analyze and produce the field texts, the Discursive Textual Analysis is adopted. The results legitimize contradictions reported in the reports of educators who teach natural sciences, as they point out deficiencies in the initial formation on the methodologies of pedagogical work in Natural Sciences.
\end{abstract}

Keywords: Science Education. Teaching Knowledge. Elementary School.

1 Mestre em Educação (PPGE/UFMT). Professora de Pedagogia, efetiva na rede municipal e estadual no município de Cuiabá - Mato Grosso. Lattes: http://lattes.cnpq.br/5174703279896310. Orcid: https:// orcid.org/0000-0003-1341-4723. E-mail: zeliasan09@gmail.com

2 Pós-doutorando em Educação em Ciências e Matemática pelo Programa de Pós-Graduação em Educação em Ciências e Matemática da Universidade Federal de Goiás (PPGECM/UFG). Doutor em Educaçấo em Ciências e Matemática pelo Programa de Pós-Graduação em Educação em Ciências e Matemática da Universidade Federal de Mato Grosso (UFMT/REAMEC). Professor Adjunto III da Área de Ensino de Química do Departamento de Química da UFMT, e dos Programas de Pós-Graduação em Educação (PPGE/UFMT), Pós-Graduação em Ensino de Ciências Naturais (PPGECN/UFMT), Campus Cuiabá, Brasil. É integrante do grupo de pesquisa (LabPEQ) Laboratório de Pesquisa e Ensino de Química. Lattes: http://lattes.cnpq.br/5484650266886844. Orcid: https://orcid.org/0000-0001-6404-2232. E-mail: marceldamascenoribeiro@gmail.com 


\section{Introdução}

O presente artigo faz parte de um recorte de dissertação de mestrado desenvolvida no Programa de Pós-Graduação em Educação da Universidade Federal de Mato Grosso (UFMT), na linha de pesquisa de Educação em Ciências e, para tanto, se justifica pela necessidade de relatar e compreender a experiência de pedagogos, ao trabalharem com a disciplina de Ciências Naturais, nos anos iniciais do Ensino Fundamental, no intuito de explicitar possíveis avanços em suas práticas pedagógicas, e possíveis necessidades formativas no contexto científico. Nesse sentido, pretende recorrer a conjecturas teóricas que aspiram elevar o fenômeno dos saberes docentes, bem como os processos de formação que realizam em meio a sua prática docente.

Ciente de que cada etapa de escolarização apresenta suas especificidades, se opta por focar nos anos iniciais do Ensino Fundamental, dedicando-lhe um maior aprofundamento nesta fase escolar de ensino.

Dessa maneira, trata-se dos professores atuantes dos anos iniciais do Ensino Fundamental, uma vez que nesta fase escolar de ensino e aprendizagem, o professor que realiza o primeiro contato com o estudante é o pedagogo, pois de acordo com o ensino regular das escolas brasileiras, este profissional que atua nas salas como unidocente se apresenta como responsável por proporcionar aos estudantes da Educação Infantil e anos iniciais do Ensino Fundamental, o ensino sistematizado dos mais diferentes conteúdos/disciplinas. Para tanto, torna-se necessário que o licenciado em pedagogia, compreendido como o mediador do processo de ensino e aprendizagem, possua conhecimento acerca dos conteúdos que serão ensinados e, tenha clareza da importância e do papel do Ensino de Ciências na formaçáo dos seus alunos, independente da faixa etária com a qual trabalha.

No entanto, de acordo com os estudos de Lorenzetti e Delizoicov (2001), a formação acadêmica dos docentes nos anos iniciais ainda oferece lacunas no que se refere à falta de conhecimento dos diversos conteúdos que agregam a área de Ciências. Do mesmo modo, as propostas curriculares concernentes à formação inicial, que contemple questôes sociais e políticas na produção do conhecimento na disciplina de Ciências ainda se encontram incipientes.

Pode-se inferir múltiplos fatores responsáveis pelo insucesso do desempenho docente com o Ensino de Ciências nos anos iniciais do Ensino Fundamental e, na expressão de Libâneo (2006), Delizoicov, Angotti e Pernambuco (2011), entre outros autores, esses fatores estão diretamente relacionados ao precário contato com os conteúdos escolares e conceitos de Ciências durante o processo de formação inicial, ou seja, não são proporcionados subsídios suficientes, a fim de propiciar o desenvolvimento de temas inerentes a esta área do conhecimento. 
Frente a essas implicaçóes e com o objetivo de compreender melhor a base de conhecimento indispensável para a atuação docente dos profissionais em pedagogia, que atuam nos anos iniciais do Ensino Fundamental, propóe-se investigar: como se configuram e se expressam saberes científicos e pedagógicos de conteúdo de Ciências Naturais subjacentes à docência de professores nos anos iniciais, ao relatarem o ensino que realizam no Ensino Fundamental?

Em busca de elucidar e tecer significados relativos às indagaçóes acima propostas se toma como objeto de análise a experiência vivida pelos professores licenciados em pedagogia, que lecionam a disciplina de Ciências Naturais nos anos iniciais do Ensino Fundamental.

\section{Saberes Docentes e Formação para o Ensino de Ciências Naturais}

As reflexóes sobre saberes docentes devem incluir, necessariamente, reflexóes sobre professores e sua prática pedagógica.

Sob a abordagem da ação pedagógica do docente, Freire (2013) descreve os saberes imprescindíveis à prática educativa, e sinaliza elementos eficazes para ação educativa do professor, tais como: criticidade, pesquisa, aceitação do novo e rejeição a qualquer forma de discriminaçấo, respeito aos saberes do aluno, rigorosidade metódica, estética e ética, reflexão crítica sobre a prática entre outros. Estes saberes explicitados por Freire avigoram a questão da complexidade do trabalho interativo desenvolvido pelo professor, pois de acordo com Tardif (2014):

Os saberes oriundos da prática de trabalho cotidiana parecem construir o alicerce da prática e da competência profissionais, pois essa experiência é para o professor, a condiçáo para aquisição e produção de seu próprio saber profissional. Ensinar é mobilizar uma ampla variedade de saberes reutilizando-os no trabalho para adaptá-los e transformá-los pelo, e para o trabalho. A experiência de trabalho, portanto, é apenas um espaço onde o professor aplica saberes, sendo ela mesma, saber do trabalho sobre saberes, ou seja, o professor faz uma releitura do que sabe naquilo que sabe fazer, produzindo, assim, sua prática profissional (TARDIF, 2014, p. 121).

Sobre esse saber, Shulman (1987) destaca sete categorias que constituem a organização didática dos aspectos que devem compor o fazer do professor, tais como: conhecimento do conteúdo, conhecimento pedagógico geral, conhecimento pedagógico do conteúdo, conhecimento do currículo, conhecimento dos alunos e de suas características, conhecimento do contexto educacional, conhecimento dos objetivos. 
Nessa perspectiva, Carvalho e Gil-Pérez (2011) reforçam que a preparação à docência é concebida, cada vez mais, como um trabalho coletivo permanente de professores em atividade. Para tanto, torna-se imperativo a formação constante, associada, em um primeiro momento, às próprias carências da formação inicial, pois muitas dificuldades da prática docente só contraem sentido quando o professor se apresenta a eles em sua própria prática docente.

Sob novas perspectivas à formação, Pimenta (2012) une o desenvolvimento e a formação da identidade aos saberes, e estes, por sua vez, as açôes reflexivas que se compóem na ação docente.

Para tanto, se faz necessária uma vigilância epistemológica para tratar os saberes científicos na Educação Básica e na Educação Superior, tanto no contexto da formação inicial, quanto no contexto da prática profissional, para constituir o entrelaçamento necessário entre os saberes científicos e pedagógicos de conteúdo, adequando com a ruptura necessária entre o saber comum e o saber científico (RIBEIRO, 2016).

Ao discutir a formação docente e, especialmente, de pedagogos para a Educação em Ciências Naturais, é importante considerar que os currículos dos cursos de Pedagogia necessitam compreender estudos que levem em consideração a crise em que a Ciência se encontra, conforme análises realizadas por Santos (2002).

A crise que ocorre dentro da própria Ciência requer que seus pressupostos sejam repensados na perspectiva de reconhecê-la como parte da cultura humana. Consequentemente, as teorias da Educação em Ciências ainda necessitam ser repensadas na formação do pedagogo.

Nessa perspectiva, Delors (1998) ressalta que um dos principais pilares para a formação inicial e continuada de professores é aprender a aprender, aprender a conhecer, a construir e a reconstruir o conhecimento, descobrir, ter curiosidade, autonomia e atenção.

Portanto, o que os torna profissionais do ensino é um processo formativo apropriado, pensado de maneira intencional sob aspectos que permitem intervir pedagógica, política e cientificamente na organização da sociedade, considerando os limites políticos, históricos e sociais também da sua própria atuação.

\section{Procedimento Metodológico}

Nesta seção se descreve o procedimento de aproximação dos participantes desta investigação. Nesse contexto, o estudo pretende se caracterizar partindo dos pressupostos da Pesquisa Narrativa (Clandinin e Connelly, 2011), guiado pela abordagem qualitativa, a qual possibilita ao investigador a busca da explicação aprofundada e da compreensão de fenômenos sociais, como estes, objeto desta investigaçáo. 
Ao interpretar as experiências como matéria-prima da pesquisa, os textos de campo, termo que Clandinin e Connelly (2011) utilizam em vez de dados, podem ser construídos por meio de narrações orais, isto é, escritos, diários de campo, notas de campo, documentos, memoriais, fotos entre outros. Estes, por sua vez, serão modificados em textos de pesquisa pelo investigador narrativo de acordo com a visão, compreensão da forma narrativa mais apropriada ao seu objeto de pesquisa, à luz dos referenciais teóricos adotados para a compreensão do fenômeno investigado. No caso desta pesquisa, utilizam-se textos de campo, transcrição de entrevistas gravadas em áudio, resposta a um questionário, diálogos em encontros informais com os sujeitos, gravados e transcritos.

\section{Registros dos Textos de Campo}

Conforme o que já foi mencionado, esta pesquisa se justifica pela necessidade DE relatar e compreender a experiência de pedagogos ao trabalharem com a disciplina de Ciências Naturais nos anos iniciais do Ensino Fundamental.

Assim, ao buscar histórias de vida para entender o fenômeno desta investigação são traçadas questóes abertas que norteiam a pesquisa, nas quais os entrevistados poderão discorrer livremente sem qualquer interferência nas respostas. Para tanto, opta-se pelos seguintes instrumentos investigativos: i) questionário cujas respostas auxiliam a constituir a caracterizaçáo dos sujeitos; ii) depoimentos dos participantes da pesquisa sob a forma de entrevista semiestruturada.

Ressalta-se, assim, que a entrevista semiestruturada teve o intuito de obter relatos de experiências inerentes às indagaçóes que orientam esta investigação e, para isso, sistematizam-se algumas questóes apenas para nortear e estimular o diálogo com os professores participantes da mesma. Para tanto, essas sáo organizadas assim em três blocos: Bloco I: Depoimento de Histórias de Vida; Bloco II: Trajetórias de Formação Inicial e Continuada; Bloco III: Saberes que subjazem à docência.

\section{O lócus, a seleção e caracterização dos sujeitos da pesquisa}

Como critérios para seleção do cenário da pesquisa, foi delineado o espaço investigativo em Escolas Públicas do Município de Cuiabá - Mato Grosso.

Com isso, a pesquisa passou a ter como lócus a Escola Municipal de Ensino Fundamental da Educação Básica (EMEB) Jesus Criança em Cuiabá - Mato Grosso, que além do critério acima explicitado ocorreu em função de suas características no contexto do município, número de profissionais 
licenciados em pedagogia e estrutura física, atendendo assim a questão norteadora desta investigação.

Ao delimitar a participação dos professores, e levando em consideração o problema de pesquisa levantado, a escolha desses professores não poderia ser aleatória ou se justificar apenas no fato de serem pedagogos, pois apesar de licenciados em pedagogia, alguns professores não exercem a unidocência ${ }^{3}$ na escola, ou seja, não lecionam nas classes dos anos iniciais do Ensino Fundamental.

A partir dessa intencionalidade investigativa foram estabelecidos os critérios de seleção definidos, quais sejam: i) Pedagogos unidocentes que estejam atuando com a disciplina de Ciências Naturais nos anos iniciais do Ensino Fundamental; ii) que lecionam na escola lócus da pesquisa; iii); que se propuseram a participar da presente pesquisa e assinaram o termo de livre consentimento esclarecido.

Assim sendo, seis professores da referida escola aceitaram ser os colaboradores desta investigação.

Dessa forma, houve o início dos procedimentos metodológicos dos registros de informaçóes, explicando aos sujeitos participantes os objetivos do estudo, ressaltando o anonimato das respostas e destacando os benefícios e riscos desta participaçáo voluntária na pesquisa. Dito isto, foi entregue aos professores o Consentimento Livre e Esclarecido (CLE) para que pudessem ler e assinar. Este documento contém todas as informaçóes acerca da pesquisa, identificando a pesquisadora, o orientador, contendo informaçóes do Comitê de Ética da UFMT, permitindo que o participante contate os responsáveis pela pesquisa a qualquer tempo. Após a delimitação do perfil dos colaboradores da pesquisa, o próximo passo foi começar a construir os textos de campo.

A primeira tarefa foi de aplicar o questionário para caracterizar os sujeitos. Desse modo, definiu-se que o primeiro momento seria a aplicação de questionário com questôes com o objetivo de fazer a caracterizaçáo dos participantes. Sendo assim, foram abordados alguns assuntos concernentes às questóes norteadoras da pesquisa, sendo esse dividido em três partes: Parte I - Dados pessoais; Parte II Formação acadêmica; Parte III - Atuação profissional.

Para isso, foi solicitado aos professores o endereço eletrônico (e-mail), para o envio do questionário. De posse do endereço virtual dos seis professores se fez o envio da carta de apresentaçáo da pesquisa, junto com o questionário, com prazo de cerca de vinte dias para retorno do mesmo respondido.

Nesta fase, dos seis professores, que haviam participado do questionário, dois não disponibilizaram em agendar as entrevistas, alegando diversos motivos,

3 Um único professor que leciona todas as disciplinas do currículo escolar nesta etapa de ensino (Educação Infantil e Ensino Fundamental) incluindo as Ciências Naturais foco desta investigação. 
sendo, contudo, respeitados em suas particularidades, portanto, totalizaram-se quatro colaboradores desta investigação, sendo três do gênero feminino e um do gênero masculino.

A seguir, são apresentados os quatro professores participantes desta investigaçáo, os quais foram registrados por meio do questionário de caracterização entregue via endereço eletrônico (e-mail), também por meio da entrevista semiestruturada.

Com o objetivo de respeitar o anonimato dos entrevistados foi utilizado um nome fictício ${ }^{4}$, para resguardar a identidade de cada colaborador da pesquisa.

\section{Quadro 1: Caracterização dos sujeitos da pesquisa}

\begin{tabular}{|l|l|}
\hline Dorina & $\begin{array}{l}\text { Natural do Paraná PR. Tem a formação inicial no magistério, em nível médio, graduação } \\
\text { em Pedagogia e Especialização em Literatura Infantil. É professora há } 20 \text { anos, sendo } \\
05 \text { anos na rede privada e } 15 \text { na rede pública de ensino. Leciona para o } 4^{\circ} \text { ano do } \\
\text { Ensino Fundamental. }\end{array}$ \\
\hline Maria & $\begin{array}{l}\text { Natural de Mato Grosso MT, graduada em Pedagogia. Possui Especialização em } \\
\text { Psicopedagogia. É professora há } 16 \text { anos. Trabalha na rede estadual e municipal de } \\
\text { ensino nos municípios de Cuiabá. }\end{array}$ \\
\hline Emília & $\begin{array}{l}\text { Natural da Bahia BA. É graduada em Pedagogia com Especialização em Didática do } \\
\text { Ensino Superior. É professora do } 2^{\circ} \text { ano do Ensino Fundamental, na rede estadual e } \\
\text { municipal de ensino no município de Cuiabá. Exerce a docência há } 22 \text { anos. }\end{array}$ \\
\hline Paulo & $\begin{array}{l}\text { Natural de Mato Grosso MT. É formado em Letras e Pedagogia. Possui Especialização } \\
\text { em Gestão Escolar. Exerce a docência há } 17 \text { anos. É professor do } 5^{\circ} \text { ano do Ensino } \\
\text { Fundamental e da } 2^{\circ} \text { fase do } 1^{\circ} \text { segmento da Educação de Jovens e Adultos (EJA). } \\
\text { Trabalha na rede municipal de ensino. }\end{array}$ \\
\hline
\end{tabular}

Fonte: Elaboração da autora, 2019.

4 Os nomes atribuídos aos professores da pesquisa são fictícios referenciando educadores que definiram novos paradigmas e trouxeram significativas contribuiçōes à educação: Paulo Reglus Neves Freire (19211997) foi um educador, pedagogo e filósofo brasileiro. É considerado um dos pensadores mais notáveis na história da pedagogia mundial. Maria Montessori (1870-1952) foi a primeira mulher a se formar em medicina na Itália. Criou o método Montessori, destacando a importância da liberdade, da atividade e do estímulo para o desenvolvimento físico e mental das crianças. Dorina Nowill (1919-2009) foi a primeira aluna cega a frequentar um curso regular, se formou como professora e criou a Fundação para o Livro do Cego no Brasil e, em 1948, fundou a primeira imprensa Braille. Emília Ferreiro (1937) revolucionou a maneira de se pensar a alfabetização. Focou seus estudos em investigaçôes sobre a escrita. Lançou o livro Psicogênese da Língua Escrita. Nova Escola: Acesso em: 19 de Fev. 2019. 


\section{Análise dos textos de campo}

Para os procedimentos de análise dos dados (material empírico) se usou o apoio da Análise Textual Discursiva (ATD), fundamentada em Moraes e Galiazzi (2011).

De acordo com os autores, a ATD se refere a um procedimento de análise de informaçấo de natureza qualitativa com a finalidade de proporcionar novas concepçóes sobre os fenômenos e discursos, bem como a reorganização das informações existentes sobre o tema investigado (MORAES e GALIAZZI, 2011).

Amparando-se neste procedimento, se objetiva aprofundar a compreensão daquilo que está sendo apresentado no material, não existindo o intuito de testar hipóteses para serem comprovadas ou rejeitadas ao término da pesquisa, ou seja, a "intenção é a compreensão, reconstruir conhecimentos existentes sobre os temas investigados" (MORAES e GALIAZZI, 2011, p. 113).

Após a aplicação do questionário e entrevista semiestruturada e estabelecendo o diálogo teórico-empírico, apresentam-se neste trabalho os resultados e as discussões contemplando o objeto de estudo exposto.

\section{Resultados e Discussão}

Para a constituição desta análise, o material empírico se encontra nos diálogos dos relatos e das histórias dos professores, que se entrelaçam com a vida pessoal e profissional ocorridos durante a entrevista semiestruturada. Com base nos referenciais teórico-metodológicos se vai tecendo este estudo para a compreensão de como os professores colaboradores configuram e expressam os saberes científicos e pedagógicos de conteúdo de Ciências Naturais subjacentes a sua docência, a partir dos enunciados de suas narrativas.

Entre as narrativas, que falam do início da docência, surgem informações, crenças, valores, e conforme Josso (2004), por meio da reflexão, emergem nas palavras revelando sentidos da formação.

Me formei no magistério pelo Instituto de Educação do Paraná. Meus pais não me apoiavam a fazer o Magistério. Nesses 20 anos de trabalho como docente, considero-me uma professora presente, com decepçôes, frustraçôes, mas com muitas expectativas de coisas novas. (Dorina, professora do $4^{\circ}$ ano).

Nasci em Cáceres no interior de Mato Grosso e vim para Cuiabá ainda menino com minha avó que me trouxe para morar com ela. São 17 anos de experiência em sala de aula. 
Sempre trabalhei com todas as disciplinas nos anos iniciais e este ano estou trabalhando também com a $1^{\circ}$ fase da EJA (Paulo-Professor do $5^{\circ}$ ano e $1^{\circ}$ fase EJA).

Por entre antigas e recentes lembranças, em um movimento cíclico, apoiado na memória, os professores manifestam como cada um se encontra na docência e o que lhes constitui a individualidade docente. Assim, Maria se manifesta nos seguintes termos:

Nasci em Cuiabá. Iniciei o meu trabalho docente com 18 anos de idade. Isso já fez que com que eu tivesse responsabilidade e compromisso.

A maneira de ser e estar na profissão tem intensa ligação com este aspecto ontológico do ser humano e com os valores e crenças, originados nesta bagagem entre a formação e o trabalho docente. Dessa forma, ao narrar sobre si, Emília se pronunciou assim:

Sou nordestina, nascida na Babia e vim para Cuiabá quando tinha apenas 15 anos de idade. Sou professora há 22 anos. Trago a poesia comigo. Meu avô era poeta. Nós somos nordestinos, criados em contato com a natureza. Eu me tornei observadora e com muita leitura porque a gente não está pronta [nunca].

De forma geral, a escolha pela profissão, segundo as narrativas desses professores, levando em conta a singularidade de cada um, incidiu pela afinidade com a docência e o gosto de ensinar, a possibilidade de melhores oportunidades de atuação no mercado de trabalho, "pela lógica da profissionalização, da influência da atmosfera sociocultural próprio da classe trabalhadora com a lógica da transformação" (TARDIF, 2014, p. 37).

Ao iniciar o diálogo sobre como avaliam sua Formação Inicial para o Ensino de Ciências. Veja-se os seguintes registros:

Dorina: em minha graduação tive 2 disciplinas dedicadas ao Ensino de Ciências, destinada à educação infantil e outra mais especifica.

Maria: o curso é mais voltado para a questão da alfabetização. Considero que fiz um curso amplo e, assim, com certeza minha formação inicial não respondeu às necessidades que vim a ter ao ministrar a disciplina. 
Emília: os conteúdos que tivemos um contato maior na faculdade foram de alfabetização e matemática, mesmo assim insuficientes.

Paulo: na graduação em pedagogia, me lembro de cursar apenas uma disciplina semestral que abordou especificamente o Ensino de Ciências. O professor responsável pela disciplina elaborou uma espécie de apostila.

Percebe-se que a maior concentração das narrativas avalia a formação inicial como precária e deficitária, surgindo como justificativas para tal julgamento, tal afirmação condiz com as queixas dos entrevistados em relação à ausência de aprofundamento nos conteúdos de Ciências, que serão ensinados para as crianças, bem como sobre as metodologias desse ensino.

Sobre a formação continuada para o Ensino de Ciências, os professores narram:

Dorina: fiz especialização em educação infantil. Participei de cursos de formação na área de letramento e alfabetização oferecidos pela rede municipal de ensino. Mas sobre Ciências da natureza nunca tive uma formação especifica e isso me faz muita falta.

Maria: tenho especialização em psicopedagogia que é um curso voltado a outras áreas do conhecimento. Por isso, não tenho muito preparo para lecionar na área das Ciências da natureza e das Ciências exatas. Sinto muita necessidade de me especializar.

Emília: em todos esses anos lecionando, nunca tive uma formação continuada sobre Ciências da natureza. Aqui na escola, participamos das rodas de conversa, e outros encontros formativos oferecidos pela secretaria de educação, mas o tema está sempre relacionado à área de linguagens e matemática.

Paulo: fiz especialização em Gestão Escolar e não havia na grade curricular nada que se referisse o ensino de Ciências. Gostaria muito de ter uma formação mais preparada nessa área do conhecimento.

Nota-se, de acordo com as narrativas, no que concerne ao Ensino de Ciências, que há pouca oferta de formação continuada aos professores. Dessa forma, todos expressam a extrema necessidade de melhorar o conhecimento na área, pois essa se desenvolve apenas no exercício da sua prática. 
Um elemento essencial, que caracteriza a formação de professores, na atualidade, pode ser definido como conceito de saber. Esse conceito aparece como componente fundante no movimento formativo dos professores.

Este saber, constituído pelos saberes que vêm da prática pessoal, logo, da experiência como professor, são estabelecidos à medida que o professor estabelece sua profissionalidade e são compreendidos como uma epistemologia da prática.

O conceito de "saber é sinônimo de conhecimento, de experiência refletida e sistematizada e, portanto, é um conhecimento reconstituído a partir da prática e na prática de formar-se continuamente" (PIMENTA, 2012 p. 32).

Para Nóvoa (1999), o saber da experiência liga o professor a outros saberes, um desses é o saber pedagógico e outro o saber científico.

Aliado e associado ao conceito de saber se vincula o conceito de profissionalidade, ou seja, o professor necessita saber para ser profissional. Assim sendo, o professor necessita do saber e este saber é unívoco de um conjunto de conteúdos e de métodos que o estimula para se tornar um profissional da Educaçáo.

Com relação ao que os professores pesquisados consideram sobre o que deve ser ensinado em Ciências nos anos iniciais do Ensino Fundamental, cada um deles explanou sob diversos aspectos.

Para Paulo, é fundamental focar nos conhecimentos pautados ao contexto em que o estudante está inserido.

Acredito que devem ser ensinados conceitos mais elaborados de fenômenos biológicos e naturais, enfim todo o meio em que o aluno se encontra inserido.

A professora Emília ressalta outras leituras como forma de referência para preparação de suas aulas:

Penso que o PCN de Ciências pode ser utilizado como base, outras vivências e outras leituras são indispensáveis para a preparação de uma aula de qualidade, que instigue os alunos a almejarem mais conhecimento.

Observa-se a questão da relação CTSA nas narrativas da professora Dorina, a qual cita a importância do emprego dos conhecimentos científicos para compreensão da vida em sociedade, apontando ao aluno uma postura responsável frente às relaçóes da vida e ao planeta e, desse modo, formar cidadáos críticos e conscientes que ajam ativamente na sociedade.

Minhas aulas de Ciências sempre foram voltadas para a questão do apoio que a Ciência nos oferece para a vida em 
sociedade, para açöes de melhoria na nossa vida e no nosso planeta, bem como as nossas responsabilidades diante desse panorama. (Dorina, professora do $4^{\circ}$ ano).

Maria retrata o modo como o currículo acontece em sala de aula, pois segundo o modo como é organizado o ensino não dá espaços para o professor agir de maneira diferente ao que o sistema impóe, uma vez que ao se referir ao modo como trabalha o Ensino de Ciências e como faz uso do livro didático, ela passa a ideia de um ensino superficial e memorístico:

Como já disse, a seleçâa de conteúdos fica por conta do curriculo que temos que seguir e as atividades por conta do livro. Com relação ao que e quando devemos trabalhar cada conteúdo. Como nos falta muito material utilizo atividades impressas, textos, curiosidades e algumas atividades que demonstrem a prática.

Dessa forma, ao analisar os currículos escolares, há uma contradição expressa entre o que orientam os documentos, o que consideram como prioridade e como os conteúdos podem ser trabalhados concernentes à sala de aula.

O professor Paulo relaciona a sua forma de ensinar Ciências com o conhecimento de senso comum que o aluno já possui, ressaltando ainda a problemática da falta de materiais para o desenvolvimento do trabalho docente. Veja-se:

Não vejo como generalizar uma resposta ou uma metodologia única, mas de forma ampla, eu utilizo diversas estratégias, conforme a necessidade dos alunos. Nas aulas de Ciências que leciono, objetivo confrontar o conhecimento de senso comum que os alunos têm sobre o conteúdo a ser ensinado e a explicação cientifica sobre o mesmo. Tento ensinar da melhor forma possivel, mas é dificil pela falta de material!

Nesse sentido, Paulo também toma como ponto balizador para o saber pedagógico do conteúdo o conhecimento prévio dos alunos. $\mathrm{O}$ mesmo acredita que esse conhecimento prévio, que se manifesta sob o nome de senso comum, é que pode se tornar a matéria-prima para o conhecimento científico.

Sobre os materiais que fazem uso durante as aulas de Ciências, o professor Paulo os relaciona à questáo da infraestrutura escolar com o ensino que realiza:

Novamente vai depender da realidade escolar que irei encontrar no momento de minha atuação. A escola possui laboratório de Ciências? Está em boas condiçōes? Se a resposta for favorável, 
poderei utilizar os materiais disponiveis, quando conveniente, dependendo de cada conteúdo que está sendo ensinado.

É notório perceber algumas expressões de insatisfação com relação à infraestrutura, recursos e materiais pedagógicos por parte dos professores investigados.

Observa-se que os professores procuram, em alguns casos, materiais de baixo ou nenhum custo, como os materiais recicláveis.

Entre os diálogos da entrevista, que abordava a temática avaliação, surgiram diversas expressóes sobre como avaliam a aprendizagem dos alunos em relação ao Ensino de Ciências e, dessa forma, os colaboradores participantes da pesquisa narram:

Dorina: a atividade avaliativa que ofereço ao aluno é a oportunidade de se expressar com suas próprias palavras sobre o que aprendeu e a partir dessas devolutivas eu avalio se há necessidade de retomar algo ou avançar no conteúdo.

Maria: não há uma avaliação específica de Ciências, no entanto, avaliamos o desempenho, a participação e a compreensão que o aluno demostra sobre o conteúdo trabalhado para dar a nota.

Emília: avalio através de avaliação diagnóstica no início $e$ formativa durante o processo de ensino.

Paulo: não sou a favor da avaliação formal. Procuro avaliar todo o processo por meio de registro escrito e das discussóes. Assim, posso confirmar se dominaram o assunto ou não para que eu possa retomá-lo.

De modo geral, os professores expressam que a concepção de avaliação está subsidiada em um processo contínuo que não se limita apenas ao momento final, mas que se propóe a acompanhar o estudante em sua trajetória de construção cotidiana, potencializando o seu desenvolvimento integral. Por isso, essa avaliação é participativa, diagnóstica e formativa.

Os processos de autoformação envolvem sentimento de inacabamento que expressam na maneira como buscam aprender, o que não sabem, quando pesquisam na Internet, em sites, blogs, artigos, filmes, revistas, a fim de criar aulas mais interessantes e atraentes aos alunos. Assim, ao narrarem sobre quais são as principais fontes de estudo para o planejamento das aulas de Ciências, Emília, Paulo, Dorina e Maria concordam em suas narrativas, tais como: troca de experiências entre os colegas de profissão, livros, artigos em internet e outros livros didáticos. Proposta Pedagógica da escola, Ciência Hoje das Crianças, artigos científicos, PCNs, livros, internet, revistas, blogs e outros. 
Ao narrarem sobre a fonte de estudo que utilizam para compor o plano de aula em Ciências, observa-se a ideia de experiência, na qual os professores compartilham experiências com outras colegas no intuito de construir e projetar as suas aulas.

Compreendendo com Larrosa (2002) que a experiência é algo que toca as pessoas, percebe-se com os participantes da pesquisa que a troca de experiências se constituiu por meio do diálogo, algo que os tocou no sentido de permitirem experimentar com seus alunos uma maneira de ensinar Ciências.

A respeito do conteúdo/conceito de Ciências que mais gosta de trabalhar, os quatro participantes da pesquisa enfatizaram os conteúdos clássicos apresentados no livro didático e que são necessários para a interpretação do mundo e as relações homem - natureza. Saúde, meio ambiente, higiene, alimentação. Ser Humano e Saúde, fenômenos naturais, corpo humano. Recursos Naturais, Classificação dos Animais, Sistema Solar, plantas, seres vivos e não vivos.

A presença de conteúdos clássicos pode indicar que tais professores têm maior conhecimento e/ou apropriação da mencionada temática, pois são os conteúdos apresentados nos livros didáticos, estabelecidos na unidade escolar do qual trabalham e, assim, sentem mais afinidade para desenvolver o trabalho em relação às Ciências nos anos iniciais com os temas sugeridos. Dessa forma, o professor muitas vezes sabe que no livro didático não está expresso o que é necessário para o aluno entender e, com isso, busca outros recursos que facilitem o ensino por meio do saber pedagógico do conteúdo.

Assim, ao dialogar com os colaboradores participantes da pesquisa se consideram importante ensinar Ciências nos anos iniciais do Ensino Fundamental, eles destacam aspectos relacionados aos fenômenos inseridos no cotidiano do estudante:

Maria: sim, pois a Ciência discute aspectos relacionados a fenômenos os quais nos deparamos no nosso dia a dia.

Emilia: sem dúvida, pois este conhecimento está relacionado à vida deles e amplia muito a sua relaçấo com o meio em que vive.

Nota-se, perante as justificativas expostas que, embora cada colaborador desta investigação tenha sua visão particular do que seja desenvolver no estudante a consciência crítica, todos defendem que o Ensino de Ciências deve proporcionar ao estudante a capacidade de se apropriar do conhecimento científico, permitindo que ele compreenda e conheça o mundo, as transformações científicas e tecnológicas, a vida em sociedade entre outros, conseguindo com que exponham considerações, análises e ponderaçóes sobre os assuntos e acontecimentos relacionados às Ciências. 


\section{Considerações}

Por entre as histórias narradas pelos professores se percebe que estes constroem saberes ao relatarem situações nas quais vão dando sentido para o Ensino de Ciências e como fazem para que o estudante compreenda e tenha mais proximidade com os conceitos científicos. Desse modo, é possível notar situaçóes ricas de interpretação em termos de saberes carregados de crenças, de valores e de maneiras de enxergar o mundo, que criam conjunturas singulares nas práticas pedagógicas que realizam. Viu-se, também, na opção metodológica da pesquisa narrativa, a possibilidade de crescimento pessoal e profissional de todos os envolvidos neste processo de investigação, pois relatar o vivido é continuamente um movimento de reflexão sobre os pressupostos de escolhas e isto pode ser entendido também como um processo formativo.

Destarte, compreende-se entre as falas, os sentimentos, e as emoçóes expressas pelos quatro professores desta investigação, o Ensino de Ciências fazendo uma travessia que tem um misto de dois tipos de saberes, ou seja, o saber transmissão (ensino como produto) e o saber experiência (ensino como processo).

Quando os professores narram as aulas, nas quais trabalham o conteúdo de Ciências fechado nesse mesmo, em cujo processo cognitivo apenas a cópia e a memorizaçáo estáo presentes, nesse momento vai sendo manifesto um saber transmissão. Conhecida também como uma tendência pedagógica tradicional, tecnicista, tal como foi expresso nos relatos do modo como, às vezes, planejam as aulas e como utilizam o livro didático.

No entanto, quando os professores constroem o conhecimento neste Ensino de Ciências, levando em conta o conhecimento que os estudantes trazem, sua cultura, seus extrapolamentos em outros níveis da vida, problematizando a partir da experiência desses estudantes, de acordo com o nível em que se encontram, ali se manifesta no Ensino de Ciências um saber da experiência que forma e transforma. Cultivar a inquietação do estudante pela aula, pelo que aprende, instigar o estudante a expor suas dificuldades para saber o que o incomoda, o que o impede de participar da aula, vai transformando o que seria um problema de sala de aula em um problema de pesquisa, unindo professor e aluno na busca de soluções conjuntas.

Este é um processo de ensinar Ciências, no qual as experiências do aluno tomam parte nesse ensino desde o que já conhecem como as exploraçóes, que podem ser feitas em salas de aula ou fora dessas para o aprendizado.

Quanto ao contexto do Ensino de Ciências, percebe-se que existe um enfrentamento de situaçóes de autonomia limitada e, ao mesmo tempo, um empenho docente, por parte dos professores, que se manifesta pela resistência 
das situações adversas de superação, que lhes constrange no ambiente de trabalho cerceador, ou seja, da resistência desses professores quanto à algumas dificuldades que encontram na caminhada pedagógica dentro da unidade em que lecionam, como: a falta de material específico, a infraestrutura precária, a falta de espaços para desenvolver as aulas de Ciências.

Contudo, o Ensino de Ciências encontra sentido, conforme o que os professores expressam, quando criam saberes pertinentes aos desafios da prática docente. Quando respeitam o nível dos alunos e não precisam avançar para outro conteúdo sem que o aluno tenha aprendido. Quando a avaliação do Ensino de Ciências é entendida como sentido pedagógico para melhoria da aprendizagem e do ensino e não como quantificação, classificação excludente. Quando é respeitado o conhecimento prévio desse aluno.

Ao dialogar entre saberes, é notório nas expressóes dos professores o esforço que fazem em adaptar os cursos desenvolvidos em outras áreas do saber, procurando utilizar teorias da aprendizagem voltadas para o avanço do aprendizado do estudante no Ensino de Ciências.

Diante do contexto, entre estes saberes, eles manifestam a construção do saber da experiência, o saber estratégico, o saber específico do conteúdo e o saber pedagógico do conteúdo no Ensino de Ciências.

O saber da experiência se apresenta diversas vezes nos relatos em suas práticas pedagógicas. Em seus discursos, os professores destacam os saberes vindos da experiência como primeira fonte de competência do saber-fazer, acenando questóes subjetivas, como: entusiasmo, amor aos alunos e, também, saberes que são compartilhados com seus colegas, seus alunos, como pertencentes ao mesmo grupo social.

Outro saber explícito por meio dos relatos é o saber estratégico, que diz respeito à capacidade de criar estratégias para privilegiar o ensino, de modo que o estudante compreenda o processo e queira aprender.

O saber específico do conteúdo, aqui adotado como saber científico, também comparece em seus relatos sobre o Ensino de Ciências em cada uma das aulas aqui apresentadas, mas não em um nível de aprofundamento desejado, pois os professores apresentaram fragilidades em relação ao conhecimento científico.

Levando-se em consideração que durante o percurso investigativo não houve observação das aulas desses professores e, portanto, são consideradas apenas as narrativas que cada professor faz de sua prática, essa condição de fragilidade aponta a possibilidade de levantar indicativos sobre prováveis obstáculos epistemológicos no desenvolvimento de suas aulas, caso as realize tal qual relataram. Esta, por sua vez, pode ocorrer em função do uso indiscriminado de termos científicos, sem a distinção de seus significados no que se refere aos termos da linguagem comum, e isto pode não somente confundir o domínio do conhecimento científico, quanto 
cristalizar conceitos equivocados, o que Bachelard (1996) chama de obstáculos à abstração, o qual é denominado de obstáculo verbal.

O obstáculo ocorre quando o professor associa uma palavra concreta a uma abstrata, ou seja, em algumas situaçóes, os professores acreditam que para promover a compreensáo dos conteúdos a serem estudados, por parte do estudante, devem fazer uso de algumas metáforas, analogias, entre outras. Todavia, o uso equivocado destes recursos pode, muitas vezes, atrapalhar e criar obstáculos para o aprendizado desse estudante.

Contudo, é importante ressaltar que estes professores não se restringem à aprendizagem da docência apenas no âmbito da formação inicial. Essas deficiências, muitas vezes, partem de sua formação antes mesmo de chegar à academia, ou seja, parte da base inicial dos anos escolares. E aí se vislumbra um processo cíclico. Um círculo vicioso no qual se apresentam como foco de análise do presente trabalho: como os pedagogos ensinam Ciências nos anos iniciais do Ensino Fundamental?

A formação de professores que trabalham com os anos iniciais de escolarização é um grande desafio, mas não é um desafio só porque são pedagogos. É um desafio, porque formar professor o é. Neste caso, não há uma procura por culpados.

A formação de pedagogos para a docência exige considerar que o magistério nos anos iniciais do Ensino Fundamental requer estudos de diversos componentes curriculares, incluindo as Ciências Naturais. Requer também preparação para o exercício da profissão em diversos espaços escolares. Requer, ainda, políticas públicas que contemplem maiores ofertas de formaçáo continuada a estes profissionais.

Portanto, julga-se que é na formação de professores que a perspectiva interdisciplinar de ensino deve ser inserida em discussão de forma intensa. $\mathrm{O}$ caráter interdisciplinar do professor não se justifica como um modismo atual, mas sim como uma necessidade inerente ao âmbito educacional.

Diante disso, destaca-se a necessidade dos cursos de formação inicial de professores que considerem, em suas propostas curriculares, as particularidades de um ensino interdisciplinar, de maneira que proporcionem possibilidades de formação de profissionais reflexivos, que conduzam um processo de ensino e aprendizagem mais expressivo, aberto ao diálogo transformador e crítico, ou seja, possibilitar a abertura de um espaço que favoreça a prática coletiva, o diálogo, a reflexão entre as diversas disciplinas, vislumbrando a construção de um aprendizado significativo e contextualizado para os estudantes, uma vez que estes serão os futuros professores do contexto educacional.

Assim, almeja-se com os resultados obtidos com o presente estudo orientar e contribuir com os debates, envolvendo saberes científicos e pedagógicos de conteúdo de Ciências Naturais para o Ensino Fundamental, e colaborar em termos mais amplos para a construção de conhecimentos de ordem teórica, 
epistemológica e metodológica para a área da Educação em Ciências e Pedagogia no Estado de Mato Grosso e no país, motivos que conduziram a este trabalho.

\section{Referências}

BACHELARD, G. A Formação do Espírito Científico. Tradução: Estela dos Santos Abreu. 1. ed. 10. reimpressão. Rio de Janeiro: Contraponto, 1996.

CARVAlHO, A. M. P. de; PÉREZ, D. Gil-. Formaçáo de professores de Ciências. 10. ed. São Paulo: Cortez, 2011.

CLANDININ, D. J.; CONNELLY, F. M. Pesquisa Narrativa: experiência e história em pesquisa qualitativa. Tradução: Grupo de pesquisa narrativa e educação de professores IEEL/UFU. Uberlândia: EDUFU, 2011.

DELIZOICOV, D.; ANGOTTI, J. A.; PERNAMBUCO, M. M. Ensino de Ciências: fundamentos e métodos. São Paulo: Cortez, 2011.

DELORS, J. Educação: um tesouro a descobrir. São Paulo: Cortez, 1998.

FREIRE, P. Pedagogia da Autonomia: Saberes necessários à prática educativa. 46.ed. Rio de Janeiro: Paz e Terra, 2013.

LARROSA, J. Notas sobre a experiências e o saber de experiência. Revista Brasileira de educaçáo. Jan/Fev/Mar/Abr, no. 19, 2002, p. 20-28.

LIBÂNEO. J. C. Didática. 2 ed. 2.reimp. São Paulo: Cortez. 2006.

LORENZETTI, L.; DELIZOICOV, Demétrio. Alfabetização Científica no Contexto das Séries Iniciais. Ensaio. Pesquisa em Educaçáo em Ciências, Belo Horizonte, v. 03, n.V.3, p. 37-50, 2001.

JOSSO, Marie-Christine. Experiências de Vida e Formaçáo. São Paulo: Cortez, 2004.

MORAES, R.; GALIAZZI, Maria do Carmo. Análise Textual Discursiva. Ijuí: Ed. Unijuí, 2011.

NOVA ESCOLA: Revista do ensino fundamental. Educabrasil. São Paulo: Midiamix, 2001. Disponível em: https://www.educabrasil.com.br/nova-escolarevista-do-ensino-fundamental/>. cesso em: 19 de fev. 2019.

NÓVOA, A. (Org). Vidas de professores. Lisboa: Porto Editora, 1999.

PIMENTA, S. G. Formação de Professores: Identidade e Saberes da Docência. In: PIMENTA, S. G. (Org.). Saberes Pedagógicos e Atividade Docente. 8ª Ed. Sáo Paulo: Cortez, 2012. 
RIBEIRO, M. T. D. Saberes Científicos e Pedagógicos de Conteúdo Expressos por Professores Egressos do Programa de Bolsa de Iniciaçáo à Docência em Química da UFMT / 2016. 160f. Tese (Doutorado) - Universidade Federal de Mato Grosso, Rede Amazônica de Educação em Ciências e Matemática, Programa de Pós-Graduação em Ensino de Ciências e Matemática, Cuiabá, 2016.

SANTOS, B. S. Um discurso sobre as Ciências. 13. ed. Porto. Ediçóes Afrontamento. 2002.

SHULMAN, L. Knowledge and Teaching: foundations of the new reform. Harvard Educ Review [Internet]. 1987 Feb [cited 2019 May 17]; 57(1):1-21.

TARDIF, M. Saberes docentes e formaçáo profissional. 17. ed. Petrópolis, RJ:Vozes, 2014. 